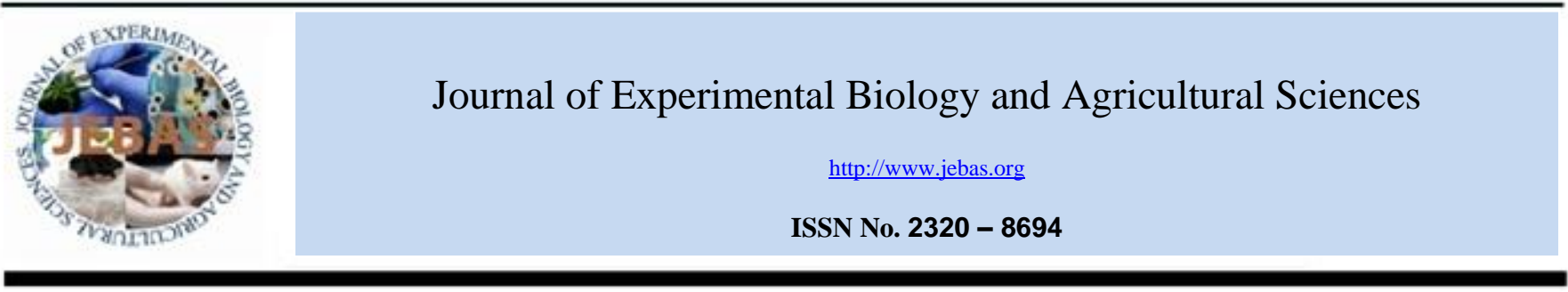

\title{
MODELING OF CORN GRAIN DRYING BY RUNGE- KUTTA METHOD
}

\section{Uziel Francisco Grajeda-González, Héctor Flores-Breceda, Juana Aranda-Ruiz, Juan Antonio Vidales-Contreras, Humberto Rodríguez-Fuentes and Alejandro Isabel Luna-Maldonado*}

Department of Agricultural and Food Engineering, Faculty of Agriculture, Autonomous University of Nuevo Leon, México

Received - March 25, 2016; Revision - April 19, 2016; Accepted - August 25, 2016

Available Online - August 31, 2016

DOI: http://dx.doi.org/10.18006/2016.4(5).462.466

\section{KEYWORDS}

Drying

Corn grain

Modeling

Runge-Kutta

\begin{abstract}
Corn grain drying modelling is used to estimate moisture loss along time, and with this information improve the drying process, maximizing energy resources. The numerical method of Runge-Kutta is an alternative for the solution of ordinary differential equations, since obtaining the coefficients of the method is possible to simulate a very real approximation of the actual behaviour of drying process. In this research, the constants of the fourth order Runge-Kutta numerical method were calculated, a determination coefficient with $\mathrm{R}^{\wedge} 2=1$ between analytical solution and a numerical method was found. The mean error between the two solutions was $3.13 \times 10^{-5}$.
\end{abstract}

* Corresponding author

E-mail: alejandro.lunaml@uanl.edu.mx (Alejandro Isabel Luna-Maldonado)

Peer review under responsibility of Journal of Experimental Biology and Agricultural Sciences.

Production and Hosting by Horizon Publisher India [HPI] (http://www.horizonpublisherindia.in/).

All rights reserved
All the article published by Journal of Experimental Biology and Agricultural Sciences is licensed under a Creative Commons Attribution-NonCommercial 4.0 International License Based on a work at www.jebas.org.

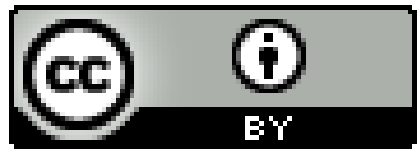




\section{Introduction}

Many problems in engineering and science can be predicted from differential equations. Numerical methods are indeed a crucial part to solve differential equations that cannot be neglected (Kanevsky et al., 2007). Nowadays, computers are used extensively to solve various differential equations. Among the most significant numerical methods, Runge- Kutta method is most prominent one and it was developed by Carl Runge and Martin Wilhelm Kutta in 1901 (Roberts, 2011). Carl Runge also developed numerical methods for solving differential equations arose from his studies of atomic spectra. These numerical methods are frequently used in these days and help in the iterations which are performed faster with modern computers (O'Connor \& Robertson, 2015a). Moreover, the thesis of Martin Wilhelm Kutta contains the Runge-Kutta method for solving ordinary differential equations (O'Connor \& Robertson, 2015b). In many cases such as model of fatigue crack growth, it is not possible solve an ordinary differential equation by analytical methods. This type of models could be solved using numeric integration schemes such as Euler, Runge-Kutta 2nd, 4th or higher order algorithms (Amann \& Kadau, 2016). Runge-Kutta method is one of most important method to solve models of continuous stages and simulate the long-time dynamical behavior of systems with special structures (Tang et al., 2016). According to Wen \& Yu (2016) Runge-Kutta has proven to be a numerical method with mathematical stability, since their results converge under given initial conditions.

High moisture content is the most important problem in the mechanized harvested corn grain. Most grain is physiologically ripe when its moisture content is around $30 \%$. In this state, it should be harvested rapidly to avoid attack in the field from predators and, in the case of rice to diminish grain loss from shattering and cracking. Therefore, farmers are required to dry their crops to solve this problem and avoid penalties by the administration of grain storage companies, normally sun drying method is used by the farmers but it is time and energy consuming. According to Proctor (1994), sun drying of grain remains the most common drying method in tropical developing countries. It is first employed when the crop is

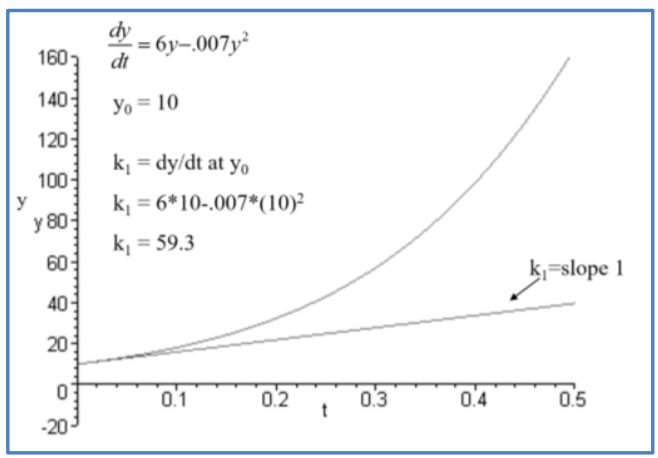

Figure 1 Slope 1 in Runge-Kutta method. standing in the field prior to harvest; maize cobs may be left on the standing plant for several weeks after attaining maturity. Although it is not required labor or other inputs field drying may render the grain subject to insect infestation and mould growth, prevent the land being prepared for the next crop and is vulnerable to theft and damage from animals. Drying in the field may also be carried out after harvest with the harvested plants laid in stacks with the grain, maize cobs or panicles raised above the ground and exposed directly to the sun. The objectives of this research were find the solution to modeling of drying corn grain with a fourth order Runge-Kutta numerical method and compare the accuracy of the numerical solution obtained by the fourth order Runge-Kutta numerical method versus the analytical solution.

\section{Materials and Methods}

Equation 1 shows the fourth order Runge Kutta method with its parameters $\mathrm{k}_{1}, \mathrm{k}_{2}, \mathrm{k}_{3} \mathrm{y} \mathrm{k}_{4}$.

$$
Y_{t+\Delta}=Y t+\Delta t\left(\frac{k_{1}}{6}+\frac{k_{2}}{3}+\frac{k_{3}}{3}+\frac{k_{4}}{6}\right)(1)
$$

Parameters $\mathrm{k}_{1}, \mathrm{k}_{2}, \mathrm{k}_{3} \& \mathrm{k}_{4}$ of fourth order Runge Kutta method can be obtained through equations 2 to 5 (Zill, 2012).

$$
\begin{gathered}
k_{1=} f^{\prime}(t, y) \\
k_{2=} f^{\prime}\left(t+\frac{\Delta_{t}}{2}, y+k_{1} \frac{\Delta_{t}}{2}\right) \ldots(3) \\
\left.k_{3=} f^{\prime}\left(t+\frac{\Delta_{t}}{2}, y+k_{2} \frac{\Delta_{t}}{2}\right) \ldots 4\right) \\
k_{4=} f^{\prime}\left(t+\Delta t, y+k_{3} \frac{\Delta_{t}}{2}\right) \ldots(5)
\end{gathered}
$$

The steps which were involved in the Excel algorithm program of Runge-Kutta methods are (1) evaluate the slope in a value of the state variable (Figure 1), (2) to calculate ylin $t+\Delta t / 2$ using $\mathrm{k} 1$ and evaluate the slope in y1 (Figure 2), (3) to calculate y2 in $t+\Delta t / 2$ using $k 2$ and evaluate the slope in y2 (Figure 3), (4) to calculate $\mathrm{y} 3$ in $\mathrm{t}+\Delta \mathrm{t} / 2$ using $\mathrm{k} 3$ and evaluate the slope in $\mathrm{y} 3$ (Figure 4) (5) to calculate weighted slope and use it to estimate $\mathrm{y}$ in $\mathrm{t}+\Delta \mathrm{t}$ (Figure 5).

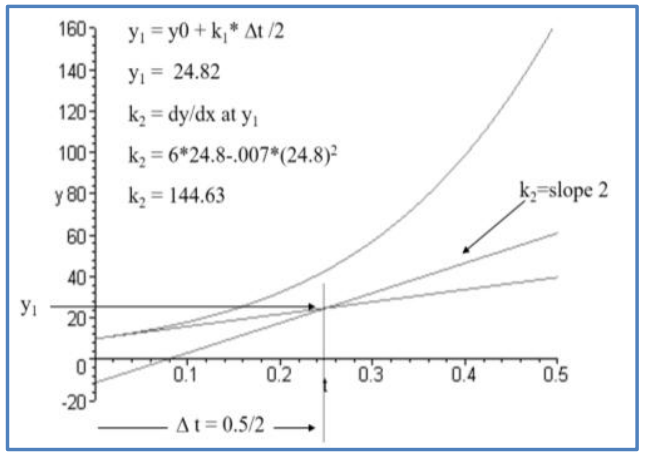

Figure 2 Slope 2 in Runge-Kutta method. 


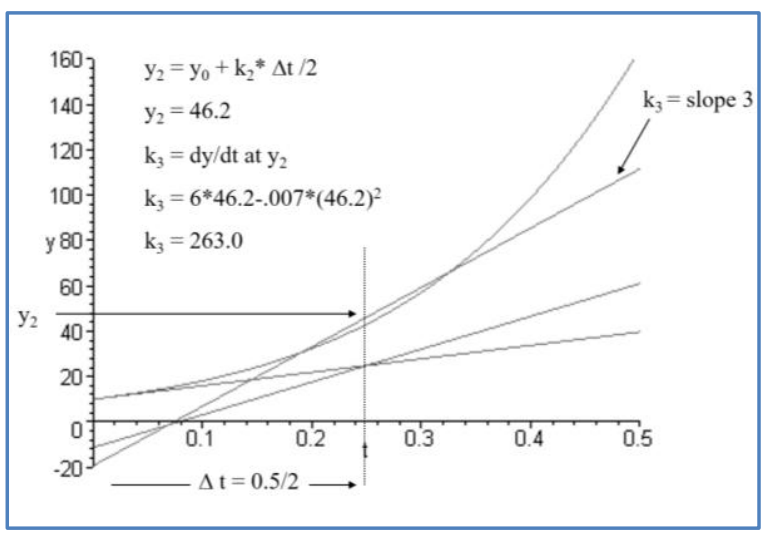

Figure 3 Slope 3 in Runge-Kutta method.

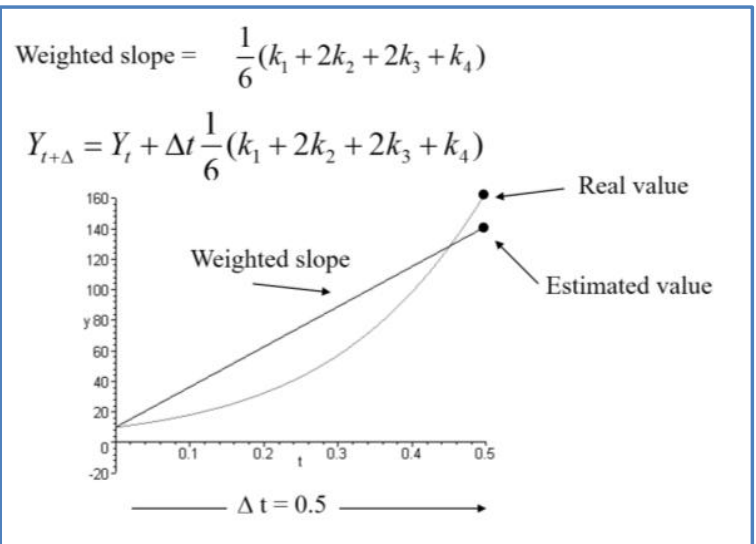

Figure 5 Weighted slope and real and estimated values in Runge-Kutta method.

To dry maize grain, a type-oven dryer was used at an initial temperature of $24^{\circ} \mathrm{C}$ to a temperature of $45^{\circ} \mathrm{C}$ and a corn grain layer of $20 \mathrm{~cm}$ depth (30 kg of mass) was placed in the oven tray and then drying process was started. After that, sampling of corn grain was made from three points of corn grain layer each hour. Corn grain masses were measured using a balance and then the moisture contents were determined by the equation of dry basis moisture (Equation 6).

$$
\% \text { Moisture }_{\text {drybasis }}=\frac{\text { Water }}{\text { Driedcorngrain }} \times 100(6)
$$

\section{Results and Discussion}

During drying test, corn grain mass and initial moisture were $40 \mathrm{~kg}$ and $30.36 \%$, respectively. The corn grain mass and final moisture were reduced $35.8 \mathrm{~kg}$ and $10.45 \%$, respectively after 8 hours of drying test (Table 1), the kinetics of drying process of corn grain was studied by Krokida et al. (2003). For modeling in Excel Worksheet the following equations on the initial moisture conditions were programmed :

$\mathrm{h}=0.5$;

Constant $\mathrm{k}=-0.13315497$;

$\mathrm{K} 1=\$ \mathrm{C} \$ 3 *(\$ \mathrm{E} \$ 3 * \mathrm{C} 7)$

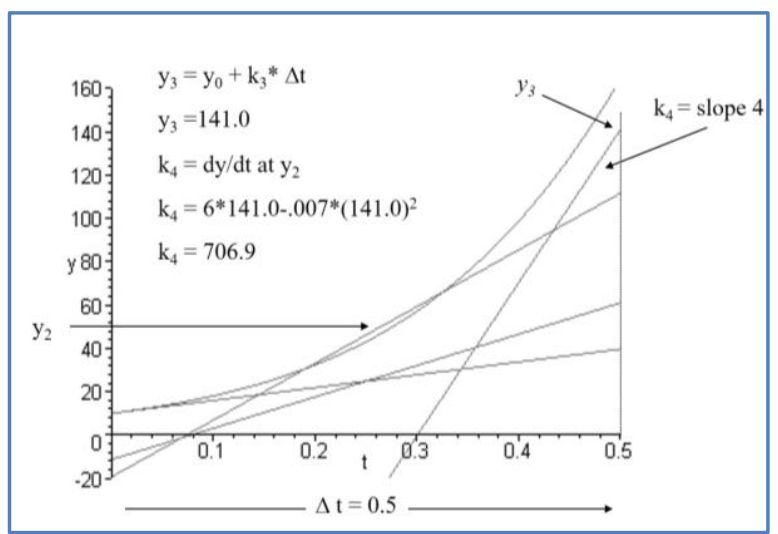

Figure 4 Slope 4 in Runge-Kutta method.

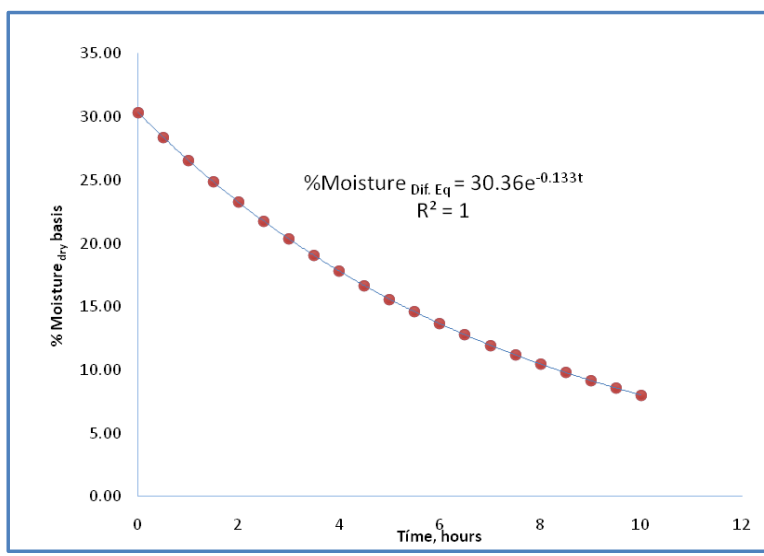

Figure 6 Prediction model of moisture percentages on a dry basis differential equation.

$\mathrm{K} 2=\$ \mathrm{C} \$ 3 *(\$ \mathrm{E} \$ 3 *(\mathrm{C} 7+(0.5 * \mathrm{D} 7))$

$\mathrm{K} 3=\$ \mathrm{C} \$ 3 *(\$ \mathrm{E} \$ 3 *(\mathrm{C} 7+(0.5 * \mathrm{E} 7)))$;

$\mathrm{K} 4=\$ \mathrm{C} \$ 3 *(\$ \mathrm{E} \$ 3 *(\mathrm{C} 7+(0.5 * \mathrm{E} 7)))$;

$\% \mathrm{H}_{\text {Runge-Kutta }}=\$ \mathrm{C} \$ 3 *(\$ E \$ 3 *(\mathrm{C} 7+\mathrm{F} 7))$

Where: $\mathrm{C}=$ time increment; $\mathrm{E}=$ intrinsic rate of grain corn drying $\mathrm{K}_{1}=$ slope $1 ; \mathrm{K}_{2}=$ slope 4

Table 1 Percentages of dry basis moisture obtained from samples of corn grain from dryer.

\begin{tabular}{|c|c|}
\hline Time (hours) & Moisture dry basis $(\%)$ \\
\hline 0 & 30.36 \\
\hline 1 & 28.00 \\
\hline 2 & 26.00 \\
\hline 3 & 24.00 \\
\hline 4 & 22.00 \\
\hline 5 & 20.98 \\
\hline 6 & 17.00 \\
\hline 7 & 13.42 \\
\hline 8 & 10.45 \\
\hline
\end{tabular}


Table 2 Percentage of corn grain dry basis moisture by differential equation, parameters $\mathrm{k}_{1}, \mathrm{k}_{2}, \mathrm{k}_{3}, \mathrm{k}_{4}$ and $\%$ of corn grain dry basis moisture by Runge-Kutta method versus time.

\begin{tabular}{|lcccccc|}
\hline Time (hours) & \% Moisture Ec.Dif & $\mathbf{k}_{\mathbf{1}}$ & $\mathbf{k}_{\mathbf{2}}$ & $\mathbf{k}_{\mathbf{3}}$ & $\mathbf{k}_{\mathbf{4}}$ & $\boldsymbol{\%}_{\text {Moisture }}$ \\
\hline 0 & 30.36000 & -2.02373 & -1.95628 & -1.95853 & -1.89318 & 30.36 \\
\hline 0.5 & 28.40225 & -1.89323 & -1.83013 & -1.83223 & -1.77110 & 28.4022454 \\
\hline 1 & 26.57074 & -1.77115 & -1.71212 & -1.71408 & -1.65689 & 26.5707359 \\
\hline 1.5 & 24.85733 & -1.65693 & -1.60171 & -1.60355 & -1.55004 & 24.8573307 \\
\hline 2 & 23.25441 & -1.55009 & -1.49842 & -1.50015 & -1.45009 & 23.2544139 \\
\hline 2.5 & 21.75486 & -1.45013 & -1.40180 & -1.40341 & -1.35658 & 21.7548606 \\
\hline 3 & 20.35201 & -1.35662 & -1.31140 & -1.31291 & -1.26910 & 20.3520056 \\
\hline 3.5 & 19.03961 & -1.26914 & -1.22684 & -1.22825 & -1.18727 & 19.0396132 \\
\hline 4 & 17.81185 & -1.18730 & -1.14773 & -1.14905 & -1.11071 & 17.81185 \\
\hline 4.5 & 16.66326 & -1.11074 & -1.07372 & -1.07495 & -1.03908 & 16.6632587 \\
\hline 5 & 15.58874 & -1.03911 & -1.00448 & -1.00563 & -0.97208 & 15.5887339 \\
\hline 5.5 & 14.58350 & -0.97210 & -0.93970 & -0.94078 & -0.90939 & 14.5834995 \\
\hline 6 & 13.64309 & -0.90942 & -0.87911 & -0.88012 & -0.85075 & 13.6430873 \\
\hline 6.5 & 12.76332 & -0.85077 & -0.82242 & -0.82336 & -0.79589 & 12.7633173 \\
\hline 7 & 11.94028 & -0.79591 & -0.76939 & -0.77027 & -0.74457 & 11.940279 \\
\hline 7.5 & 11.17032 & -0.74459 & -0.71977 & -0.72060 & -0.69655 & 11.170314 \\
\hline 8 & 10.45000 & -0.69657 & -0.67336 & -0.67413 & -0.65164 & 10.45 \\
\hline 8.5 & 9.77614 & -0.65166 & -0.62994 & -0.63066 & -0.60962 & 9.77613516 \\
\hline 9 & 9.14573 & -0.60963 & -0.58932 & -0.58999 & -0.57031 & 9.14572429 \\
\hline 9.5 & 8.55597 & -0.57032 & -0.55131 & -0.55195 & -0.53353 & 8.55596526 \\
\hline 10 & 8.00424 & -0.53354 & -0.51576 & -0.51635 & -0.49913 & 8.00423665 \\
\hline
\end{tabular}

$\mathrm{h}=0.5 ;$ Constant $\mathrm{k}=-0.13315497$

$\% \mathrm{H}_{\mathrm{n}+1}=\mathrm{y}_{\mathrm{n}}+\left[\mathrm{K}_{1} / 6+\mathrm{K}_{2} / 3+\mathrm{K}_{3} / 3+\mathrm{K}_{4} / 6\right]$, moisture content in corn grain.

Exact or analytical solution of the differential equation of corn drying of maize grain was $\%$ Moisture ${ }_{\text {Dif.Eq }}=30.36 \mathrm{e}^{\wedge}(-0.133 \mathrm{t})$, the solving to the mathematical model is observed with Martinello et al. (2013) with a determination coefficient equals to 1 (Figure 6).

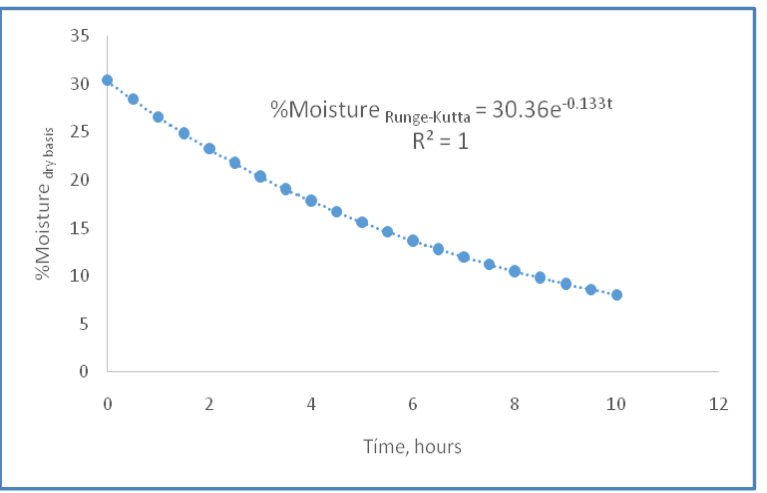

Figure 7 Prediction model of moisture percentages on a dry basis with the Runge -Kutta numerical method.

Table 2 shows the percentages of corn grain moisture on dry basis obtained by differential equation, parameters k1, k2, k3 and $\mathrm{k} 4$ and corn grain moisture on dry basis obtained by
Runge- Kutta method. The average error between the percentages of corn grain moisture obtained with the differential equation and the Runge-Kutta method was 3.138 $\mathrm{x} 10^{\wedge}-5$.The solution for drying grain corn by the Runge - Kutta method was \%Moisture ${ }_{(\text {Runge-Kutta })}=30.36 \mathrm{e}^{\wedge}(-0.133 \mathrm{t})$ with a determination coefficient equals to 1 (Figure 7). It was observed that error between methods to determine corn grain moisture contents is relatively low.

\section{Conclusions}

The moisture content was predicted according to an exponential model, which was "\%Moisture $($ Runge-Kutta) $=$ $30.36 \mathrm{e}^{\wedge}(-0.133 \mathrm{t})$ " with a determination coefficient of $\mathrm{R}^{2}=1$. Further, the error between the percentages of moisture obtained with the differential equation and the Runge-Kutta numerical method was $3.138 \times 10^{\wedge}-5$.

\section{Acknowledgements}

This study was performed thanks to the financial support from National Council of Science and Technology of Mexico and Mexican Ministry of Education.

\section{Conflict of interest}

Authors would hereby like to declare that there is no conflict of interests that could possibly arise. 


\section{References}

Amann C, Kadau K (2016) Numerically efficient modified Runge-Kutta solver for fatigue crack growth analysis. Engineering Fracture Mechanics 161: 55-62. DOI:10.1016/j.engfracmech.2016.03.021.

O'Connor JJ, Robertson EF (2015a) "Carl David Tolmé Runge", MacTutor History of Mathematics archive, University of St Andrews. Available on www-history.mcs.standrews.ac.uk/Biographies/Runge.html access on 2016.

O'Connor JJ, Robertson EF (2015b) "Martin Wilhelm Kutta", MacTutor History of Mathematics archive, Universidad de Saint Andrews. Available on http://www-history.mcs.standrews.ac.uk/Mathematicians/Kutta.html access on 2016

Kanevsky A, Carpenter MH, Gottlieb D, Hesthaven JS (2007) Application of implicit-explicit high order Runge-Kutta methods to discontinuous-Galerkin schemes. Journal of Computational Physics 225: 1753-1781. DOI: 10.1016/j.jcp.2007.02.021.

Krokida MK, Karathanos VT, Maroulis ZB, Marinos-Kouris D (2003) Drying kinetics of some vegetables. Journal of Food Engineering 59 : 391-403. DOI: 10.1016/S02608774(02)00498-3.
Martinello MA, Muñoz DJ, Giner SA (2013) Mathematical modelling of low temperature drying of maize: Comparison of numerical methods for solving the differential equations. Biosystems Engineering 114 : 187-194.

Proctor DL (1994) Grain Storage Techniques: Evolution and trends in developing countries (No. 109). Food \& Agriculture Organization.

Roberts C (2011) Ordinary differential equations: applications, models, and computing. CRC Press.

Tang W, Lang G, Lang W, Luo X (2016) Construction of symplectic (partitioned) Runge-Kutta methods with continuous stage. Applied Mathematics and Computation 286: 279-287. DOI: 10.1016/j.amc.2016.04.026.

Wen L, Yu Y (2016) Convergence of Runge-Kutta methods for neutral delay integro-differential equations. Applied Mathematics and Computation 282: 84-96. DOI: 10.1016/j.amc.2016.02.001.

Zill D (2012) A First Course in Differential Equations with Modeling Applications. Brooks Cole Publishing Company 11: $17-25$. 